\title{
Implementasi Model Problem Based Learning Bermediakan Slide Presentasi Berbasis Unjuk Kerja untuk Meningkatkan Kompetensi Pengetahuan IPA
}

\author{
I Md. Adi Arnawa ${ }^{\text {* }}$ (iD \\ ${ }^{1}$ Pendidikan Profesi Guru, Universitas Pendidikan Ganesha, Singaraja, Indonesia \\ *Corresponding author: adi.arnawa@gmail.com
}

\section{Abstrak}

Pembelajaran IPA di SD dalam pencapaian kompetensi pengetahuan yang optimal belum dilaksanakan secara maksimal Penelitian ini bertujuan menganalisis kompetensi pengetahuan IPA melalui implementasi model problem based learning bermediakan slide presentasi berbasis unjuk kerja dalam pembelajaran daring. Penelitian ini merupakan penelitian tindakan kelas yang dilaksanakan dalam dua siklus. Subjek penelitian adalah siswa kelas VIB yang berjumlah 36 siswa. Data kompetensi pengetahuan IPA dikumpulkan dengan menggunakan tes. Data yang terkumpul dianalisis dengan analisis statistik deskriptif kuantitatif. Hasil penelitian menunjukkan bahwa pada pra siklus diperoleh persentase rata-rata kompetensi pengetahuan IPA yaitu 64\% dikategorikan rendah dengan ketuntasan klasikal mencapai 25\%. Setelah dilakukan perbaikan pembelajaran pada siklus I, persentase rata-rata kompetensi pengetahuan IPA menjadi $68 \%$ dikategorikan sedang dengan ketuntasan klasikal mencapai 67\%. Pada siklus II meningkat menjadi 81\% dikategorikan tinggi dengan ketuntasan klasikal mencapai $83 \%$. Berdasarkan hasil penelitian tersebut, dapat disimpulkan bahwa implementasi model problem based learning bermediakan slide presentasi berbasis unjuk kerja dalam pembelajaran daring dapat meningkatkan kompetensi pengetahuan IPA siswa kelas.

Kata kunci: PBL, Slide Presentasi Unjuk Kerja

\section{Abstract}

Science learning in elementary schools in achieving optimal knowledge competencies has not been carried out optimally. This study aims to analyze science knowledge competencies through the implementation of a problem-based learning model using performance-based presentation slides in online learning. This research is a classroom action research conducted in two cycles. The research subjects were students of class VIB, totaling 36 students. Science knowledge competency data were collected using tests. The collected data were analyzed by quantitative descriptive statistical analysis. The results showed that in the pre-cycle the average percentage of science knowledge competence was $64 \%$ categorized as low with classical completeness reaching 25\%. After improving learning in the first cycle, the average percentage of science knowledge competence became $68 \%$ categorized as moderate with classical completeness reaching $67 \%$. In the second cycle, it increased to $81 \%$ which was categorized as high with classical completeness reaching $83 \%$. Based on the results of the study, it can be concluded that the implementation of the problem-based learning model using performance-based presentation slides in online learning can improve the scientific competence of class students.

\section{INTRODUCTION}

Pandemi Covid 19 yang telah menjadi pandemi global saat ini menuntut pemerintah melalui Kementerian Pendidikan dan Kebudayaan (Kemendikbud) dengan adanya Surat Edaran nomor 36962/MPK.A/HK/2020 perihal pembelajaran secara daring, bekerja dan belajar dari rumah dalam rangka pencegahan COVID 19 bagi guru dan bagi siswa untuk semua jenjang di seluruh Indonesia. Kegiatan BDR (Belajar dari Rumah) juga dilaksanakan untuk memberikan pengalaman yang bermakna bagi siswa, tanpa terbebani tuntutan menuntaskan seluruh capaian kurikulum. Sehingga, BDR dapat difokuskan pada pendidikan kecakapan hidup, antara lain mengenai pandemi Covid-19. Karena itu, pedoman ini mengedepankan pola interaksi dan komunikasi yang positif antara guru dengan orang tua atau wali siswa. Metode BDR mengedepankan pembelajaran jarak jauh dalam jaringan

$\begin{array}{ll}\text { History: } & \\ \text { Received } & \text { : November 16, 2020 } \\ \text { Revised } & \text { : December 11, 2020 } \\ \text { Accepted } & \text { : April 26, 2021 } \\ \text { Published } & \text { : May 25, 2021 }\end{array}$


(daring) atau online (Permata \& Bhakti, 2020; Santosa et al., 2020; Windhiyana, 2020). BDR dapat dilakukan melalui video conference, digital documents, dan sarana daring lainnya (Daheri et al., 2020; Nurul Hidayah, 2020; Sadikin \& Hamidah, 2020) Metode ini menggunakan gawai (gadget) maupun laptop melalui beberapa portal dan aplikasi pembelajaran daring serta pembelajaran jarak jauh luar jaringan (luring) atau offline.

Mengacu pada hal tersebut, pelaksanaan BDR di SD No.3 Legian merupakan gabungan pembelajaran daring dan luring. Pembelajaran daring dilaksanakan melalui WA (WhatsApp) grup masing-masing kelas, google form, dan quizziz. Melalui WA grup, guru menjalin komunikasi dengan orangtua dan siswa untuk memberikan tugas-tugas dan materi yang sesuai dengan KD, serta memberikan materi kecakapan hidup mengenai covid-19. Kemudian dengan google form dan quizziz, guru memberikan soal-soal penilaian harian (PH), Penilaian Akhir Semester (PAS) serta Ujian Sekolah (US) bagi anak-anak kelas VI yang dijawab oleh siswa secara online. Sedangkan untuk pembelajaran luring, guru menugaskan menjawab pertanyaan terkait materi TVRI dan tugas-tugas yang diberikan dalam bentuk laporan. Hasil tugas-tugas siswa secara daring dibuktikan melalui foto dan video yang dikirimkan oleh siswa. Sedangkan pelaksanaan pembelajaran luring, guru menugaskan siswa untuk menjawab pertanyaan terkait materi TVRI dan tugas-tugas lain yang dapat dikerjakan siswa secara luring.

Namun seiring berjalannya waktu, kebijakan belajar dari rumah terus diperpanjang meski sudah ada tahapan new normal di beberapa sektor. Banyak permasalahan baru yang muncul terkait kebijakan tersebut. Diantaranya terjadi kejenuhan pada diri siswa dalam mengikuti pembelajaran terutama terjadi di kelas VI B SD No. 3 Legian. Siswa mulai jenuh mengikuti kegiatann belajar dari rumah dan terkadang siswa mengalami kebingungan dalam memahami materi pembelajaran yang diajarkan oleh guru melalui WhatsApp Group. Dampak yang terjadi ialah menurunnya motivasi belajar siswa dalam mengikuti pembelajaran daring. Penurunan motivasi belajar siswa ini ternyata berbanding lurus dengan menurunnya hasil belajar yang diperoleh siswa terutama terlihat pada hasil belajar aspek pengetahuan IPA yang diperoleh siswa saat Penilan Tengah Semester Ganjil. Hasil belajar pengetahuan IPA siswa kelas VI B di SD No. 3 Legian masih rendah, bila dibandingkan dengan KKM satuan pendidikan 70 nilai rata-rata yang dicapai oleh siswa masih di bawah KKM.

Kompetensi Pengetahuan IPA diperoleh secara optimal, ketika siswa mampu mengolah dan memahami materi pembelajaran yang diberikan. Hal tersebut tentu tidak terlepas dari peran seorang guru yang dituntut untuk melakukan pembaharuan-pembaharuan proses pembelajaran dalam mengelola kelas secara daring agar kondusif yang dapat membantu siswa dalam mencapai kompetensi pengetahuan IPA yang optimal. Kompetensi pengetahuan IPA tidak semata mata bergantung pada apa yang dijelaskan guru, melainkan apa yang diperoleh anak dan bagaimana anak mengolah informasi tersebut berdasarkan pemahaman yang telah dimiliki sebelumnya (Suantara et al., 2019; Wiranti et al., 2017). Peran guru dan siswa harus beriringan dan jika itu terjadi maka akan berdampak pada ketercapaian kompetensi pengetahuan yang diinginkan. Namun kenyataan yang terjadi di Lapangan tidak sesuai dengan yang diharapkan. Pembelajaran IPA di SD dalam pencapaian kompetensi pengetahuan yang optimal belum dilaksanakan secara maksimal, demikian halnya yang terjadi SD No. 3 Legian.

Permasalahan tersebut jika dibiarkan akan berpengaruh terhadap proses dan hasil pembelajaran. Diperlukan sebuah solusi untuk masalah tersebut, salah satunya ialah model pembelajaran yang dapat mengarahkan siswa berpikir dengan menyajikan tugas-tugas dan aktifitas yang sesuai, membantu siswa mengaitkan materi belajar mereka dengan apa yang mereka pelajari pada materi belajar lain, dan dengan apa yang mereka pelajari diluar sekolah, menciptakan lingkungan belajar positif yang menggugah rasa ingin tahu siswa, dan membantu siswa belajar bagaimana belajar. Salah satu model pembelajaran yang dapat 
dijadikan solusi atas permasalah tersebut adalah model pembelajaran problem based learning.

Problem Based Learning atau yang dikenal dengan model pembelajaran berbasis masalah dikembangkan berdasarkan teori psikologi kognitif modern yang menyatakan belajar adalah suatu proses pembelajaran dimana pembelajar secara aktif mengkonstruksi pengetahuannya (Atminingsih et al., 2019; Yunita \& Tristiantari, 2019). Problem based learning merupakan pembelajaran yang menggunakan berbagai kemampuan berpikir dari peserta didik secara individu maupun kelompok serta lingkungan nyata untuk mengatasi permasalahan sehingga bermakna, relevan, dan kontekstual. Implementasi problem based learning memiliki kelebihan antara lain: 1) pembelajaran berpusat pada peserta didik; 2) mengembangkan pengendalian diri peserta didik; 3) memungkinkan peserta didik mempelajari peristiwa secara multidimensi dan mendalam; 4) mengembangkan keterampilan pemecahan masalah; 5) mendorong peserta didik mempelajari materi dan konsep baru ketika memecahkan masalah; 6) mengembangkan kemampuan sosial dan keterampilan berkomunikasi yang memungkinkan mereka belajar dan bekerja dalam tim; 7) mengembangkan keterampilan berpikir ilmiah tingkat tinggi/kritis; 8) mengintegrasikan teori dan praktik yang memungkinkan peserta didik menggabungkan pengetahuan lama dengan pengetahuan baru; 9) memotivasi pembelajaran; 10) peserta didik memperoleh keterampilan mengelola waktu; dan 11) pembelajaran membantu cara peserta didik untuk belajar sepanjang hayat (Eismawati et al., 2019; Pratiwi \& Setyaningtyas, 2020). Pada implementasi problem based learning ini, akan dipadukan dengan media power point.

Media power point adalah program aplikasi presentasi yang merupakan salah satu program aplikasi dibawah microsoft office program komputer dan tampilan ke layar menggunakan bantuan LCD proyektor (Cahyaningsih et al., 2020; Mandasari, 2021). Beberapa hal yang menjadikan media power point ini menarik untuk digunakan sebagai alat persentasi dalam menyampaikan pembelajaran adalah berbagai kemampuan pengolahan teks, warna dan gambar, serta animasi-animasi yang bisa diolah sendiri sesuai kreativitas penggunaannya (Jamilah, 2019; Minardi \& Akbar, 2020; Wahidi, 2017). Media slide presentasi berbasis unjuk kerja adalah media berupa slide presentasi dari aplikasi power point yang menuntut respon dari siswa berupa keterampilan melakukan suatu aktivitas atau perilaku sesuai dengan tuntutan kompetensi. Belum ada penelitian yang mendalam mengenai penerapan model problem based learning bermediakan slide presentasi berbasis unjuk kerja pada pembelajaran daring di sekolah dasar.

Beberapa penelitian yang relevan dengan penelitian ini dilakukan oleh (Mandasari, 2021) menemukan bahwa pembelajaran pada Tema 8 menggunakan model pembelajaran berbasis masalah berbantuan media power point dapat meningkatkam aktivitas dan hasil belajar siswa. Penelitian yang dilakukan oleh (Cahyaningsih et al., 2020) menemukan bahwa model Project Based Learning berbantu multimedia power point efektif terhadap hasil belajar siswa. Kemudian penelitian lain juga menemukan bahwa ahwa ada peningkatan hasil belajar IPS setelah menerapkan model pembelajaran Circuit Learning berbantuan media Microsoft Power Point (Putra \& Setiawan, 2019). Tujuan penelitian ini adalah menganalisis kompetensi pengetahuan IPA melalui implementasi model problem based learning bermediakan slide presentasi berbasis unjuk kerja dalam pembelajaran daring.

\section{MATERIALS AND METHODS}

Penelitian ini merupakan penelitian tindakan kelas (PTK). Penelitian ini dilaksanakan di SD No. 3 Legian pada bulan November tahun pelajaran 2020/2021. Subjek penelitian adalah siswa kelas VI B SD No. 3 Legian, Kecamatan Kuta tahun pelajaran 2020/2021 yang berjumlah 36 siswa yang terdiri dari 22 siswa laki-laki dan 14 siswa perempuan. Siswa kelas 
VIB dipilih sebagai subjek penelitian karena kompetensi pengetahuan IPA siswa pada kelas ini perlu ditingkatkan lagi. Penelitian ini dilaksanakan dalam dua siklus. Data yang dikumpulkan dalam penelitian ini adalah data kompetensi pengetahuan IPA siswa. Berdasarkan data tersebut maka metode pengumpulan data yang akan digunakan adalah metode tes. Data kompetensi pengetahuan IPA siswa dikumpulkan dengan tes kompentensi belajar yang berupa tes objektif. Data yang terkumpul dianalisis dengan analisis statistik deskriptif dan deskriptif kuantitatif. Adapun indikator keberhasilan dari penelitian ini yaitu (1) persentase kompetensi pengetahuan IPA siswa kelas VI B SD No. 3 Legian minimal 80\% atau minimal berada pada kategori tinggi dan (2) ketuntasan klasikal yang diharapkan pada pembelajaran ini yaitu minimal $80 \%$ siswa mencapai kriteria ketuntasan minimal (KKM) yang ditentukan oleh sekolah. KKM yang ditentukan oleh SD No. 3 Legian adalah 70.

\section{RESULTS AND DISCUSSION}

Pada pra siklus diperoleh persentase kompetensi pengetahuan IPA siswa sebesar 64\% yang berada pada kategori rendah dengan ketuntasan klasikal sebesar 25\%. Informasi tersebut selanjutnya dijadikan sebagai refleksi awal untuk melakukan perbaikan proses pembelajaran pada siklus I. Persentase rata-rata kompetensi pengetahuan IPA siklus I adalah 68\%. Jika angka persentase rata-rata tersebut dikonversikan dengan PAP kompetensi pengetahuan IPA, maka angka rata-rata tersebut berada pada kategori sedang. Ketuntasan belajar siswa secara klasikal mencapai 67\%. Ini berarti bahwa dari 36 siswa hanya 24 siswa yang tuntas dan 12 siswa belum tuntas atau belum mencapai nilai sesuai dengan KKM.

Persentase rata-rata kompetensi pengetahuan IPA siswa pada siklus II adalah $81 \%$. Jika angka persentase rata-rata tersebut dikonversikan dengan PAP kompetensi pengetahuan IPA, maka angka rata-rata tersebut berada pada kategori tinggi. Ketuntasan belajar siswa secara klasikal mencapai $83 \%$. Ini berarti bahwa dari 36 siswa hanya 30 siswa yang tuntas dan 6 siswa belum tuntas atau belum mencapai nilai sesuai dengan KKM. Adapun rekapitulasi kompetensi pengetahuan IPA dan ketuntasan klasikal siswa kelas VIB SD No. 3 Legian pada pra siklus, siklus I, dan siklus II dapat dilihat pada Tabel 1.

Tabel 1. Rekapitulasi Kompetensi Pengetahuan IPA

\begin{tabular}{lcccc}
\hline \multirow{2}{*}{ Siklus } & \multicolumn{4}{c}{ Kompetensi Pengetahuan IPA } \\
\cline { 2 - 5 } & $\begin{array}{c}\text { Jumlah Siswa } \\
\text { Tuntas }\end{array}$ & $\begin{array}{c}\text { Jumlah Siswa } \\
\text { Belum Tuntas }\end{array}$ & $\begin{array}{c}\text { Rata- Rata } \\
\text { Kelas }\end{array}$ & $\begin{array}{c}\text { Ketuntasan } \\
\text { Klasikal }\end{array}$ \\
\hline Prasiklus & 9 & 27 & 64 & $25 \%$ \\
Siklus 1 & 24 & 12 & 68 & $67 \%$ \\
Siklus 2 & 30 & 6 & 81 & $83 \%$ \\
\hline
\end{tabular}

Berdasarkan hasil penelitian pada siklus I, diperoleh informasi bahwa implementasi model Problem Based Learning dapat meningkatkan kompetensi pengetahuan IPA. Persentase rata-rata kompetensi pengetahuan IPA siswa pada siklus I adalah 68\%. Jika angka persentase rata-rata tersebut dikonversikan dengan PAP kompetensi pengetahuan IPA, maka kompetensi pengetahuan IPA pada siklus I berada kategori sedang. Ini berarti sudah terjadi peningkatan kompetensi pengetahuan IPA dari sebelum penelitian yang hanya $64 \%$ atau berada pada kategori rendah. Ketuntasan belajar siswa secara klasikal mencapai $67 \%$. Ini berarti bahwa dari 36 siswa hanya 24 siswa yang tuntas dan 12 siswa belum tuntas atau belum mencapai nilai sesuai dengan KKM.

Beberapa kelemahan-kelemahan yang ditemukan pada siklus I yaitu siswa belum terbiasa mengikuti proses pembelajaran dengan mengimplementasikan model pembelajaran Problem Based Learning bermediakan slide presentasi berbasis unjuk kerja secara daring, 
siswa kurang aktif dan belum mampu untuk mengemukakan ide-idenya sehingga kemampuan dalam memecahkan permasalahan masih perlu ditingkatkan lagi, dan hasil evaluasi pada siklus I belum optimal. Hasil refleksi kelemahan-kelemahan yang ditemukan pada siklus I kemudian dijadikan sebagai pedoman perbaikan tindakan pembelajaran pada siklus II sehingga diperoleh hasil yang lebih baik. Berdasarkan hasil diskusi, diperoleh solusi untuk mengatasi kelemahan-kelemahan yang ditemukan pada pelaksanaan siklus I yaitu menggunakan metode pembelajaran yang variatif sehingga siswa merasa lebih tertanntang, terlibat aktif dalam proses pembelajaran sehingga siswa lebih mampu mengungkapkan ideide dalam menyelesaikan masalah, selain itu peneliti juga memotivasi dan menuntun siswa untuk dapat mengungkapkan ide-idenya dalam menyelesaikan masalah. memotivasi siswa agar lebih aktif membaca sumber untuk menyelesaikan masalah yang diberikan.

Setelah diadakan perbaikan dari siklus I pada siklus II diperoleh persentase rata-rata kompetensi pengetahuan IPA adalah $81 \%$ Jika angka persentase rata-rata tersebut dikonversikan dengan PAP kompetensi pengetahuan IPA, maka angka rata-rata tersebut berada pada kategori tinggi. Ini berarti sudah terjadi peningkatan kompetensi pengetahuan IPA dari pelaksanaan pembelajaran siklus I yang hanya $68 \%$ atau berada pada kategori sedang. Ketuntasan klasikal sudah mencapai $83 \%$. Meskipun telah terjadi peningkatan kompetensi pengetahuan IPA siswa pada siklus II, namun masih ada beberapa siswa yang memiliki kompetensi pengetahuan yang masih kurang dari KKM. Ini tentu memerlukan penanganan khusus selain dengan memperbaiki proses pembelajarannya. Penanganan yang bisa dilakukan misalnya melakukan bimbingan pembelajaran secara individual serta melakukan remedial pada siswa tersebut.

Secara umum, pelaksanaan siklus II melalui implementasi model problem based learning bermediakan slide presentasi berbasis unjuk kerja sudah berjalan dengan baik sehingga terjadi peningkatan kompetensi pengetahuan IPA, dan ketuntasan klasikal siswa dari pelaksanaan siklus II. Peningkatan-peningkatan tersebut sudah mencapai indikator keberhasilan yang telah ditetapkan dalam penelitian ini, dengan kompetensi pengetahuan IPA berada pada kategori tinggi, dan ketuntasan klasikal sudah mencapai 83\% dari keseluruhan siswa pada akhir siklus II. Hal ini dikarenakan pada siklus II, dengan penerapan model problem based learning bermediakan slide presentasi berbasis unjuk kerja dapat meningkatkan motivasi siswa untuk belajar. Selain itu, penerapan model problem based learning bermediakan slide presentasi berbasis unjuk kerja memungkinkan peserta didik mempelajari peristiwa secara multidimensi dan mendalam dan dapat mengembangkan keterampilan pemecahan masalah siswa. Hal tersebut tentu akan berdampak pada hasil belajar siswa terutama pada kompetesi pengetahuan IPA.

Kompetensi Pengetahuan IPA diperoleh secara optimal, ketika siswa mampu mengolah dan memahami materi pembelajaran yang diberikan. Hal tersebut tentu tidak terlepas dari peran seorang guru yang dituntut untuk melakukan pembaharuan-pembaharuan proses pembelajaran dalam mengelola kelas secara daring agar kondusif yang dapat membantu siswa dalam mencapai kompetensi pengetahuan IPA yang optimal. Kompetensi pengetahuan IPA tidak semata mata bergantung pada apa yang dijelaskan guru, melainkan apa yang diperoleh anak dan bagaimana anak mengolah informasi tersebut berdasarkan pemahaman yang telah dimiliki sebelumnya (Suantara et al., 2019; Wiranti et al., 2017). Peran guru dan siswa harus beriringan dan jika itu terjadi maka akan berdampak pada ketercapaian kompetensi pengetahuan yang diinginkan.

Implementasi model problem based learning bermediakan slide presentasi merupakan salah satu strategi pembelajaran yang menggunakan berbagai kemampuan berpikir dari peserta didik secara individu maupun kelompok serta lingkungan nyata untuk mengatasi permasalahan sehingga bermakna, relevan, dan kontekstual. Implementasi Model PBL memiliki kelebihan antara lain 1) pembelajaran berpusat pada peserta didik; 2) 
mengembangkan pengendalian diri peserta didik; 3) memungkinkan peserta didik mempelajari peristiwa secara multidimensi dan mendalam; 4) mengembangkan keterampilan pemecahan masalah; 5) mendorong peserta didik mempelajari materi dan konsep baru ketika memecahkan masalah; 6) mengembangkan kemampuan sosial dan keterampilan berkomunikasi yang memungkinkan mereka belajar dan bekerja dalam tim; 7) mengembangkan keterampilan berpikir ilmiah tingkat tinggi/kritis; 8) mengintegrasikan teori dan praktik yang memungkinkan peserta didik menggabungkan pengetahuan lama dengan pengetahuan baru; 9) memotivasi pembelajaran; 10) peserta didik memperoleh keterampilan mengelola waktu; dan 11) pembelajaran membantu cara peserta didik untuk belajar sepanjang hayat (Eismawati et al., 2019; Pratiwi \& Setyaningtyas, 2020). Selain itu pula, dampak dari model problem based learning dapat meningkatkan daya ingat siswa terhadap pengetahuan, siswa juga mengalami peningkatan pemahaman tentang materi pembelajaran, terjadi penigkatan pengintegrasian pengetahuan, dapat mengembangkan tim kerja, kepemimpinan, dan kemampuan tim sosial, dapat mengembangkan kemampuan belajar sepanjang hayat, dan mampu memotivasi siswa dalam belajar (Diantari et al., 2014; Elita et al., 2019; Sariningsih \& Purwasih, 2017).

Media power point adalah program aplikasi presentasi yang merupakan salah satu program aplikasi dibawah microsoft office program komputer dan tampilan ke layar menggunakan bantuan LCD proyektor (Cahyaningsih et al., 2020; Mandasari, 2021). Beberapa hal yang menjadikan media power point ini menarik untuk digunakan sebagai alat persentasi dalam menyampaikan pembelajaran adalah berbagai kemampuan pengolahan teks, warna dan gambar, serta animasi-animasi yang bisa diolah sendiri sesuai kreativitas penggunaannya (Jamilah, 2019; Minardi \& Akbar, 2020; Wahidi, 2017). Media slide presentasi berbasis unjuk kerja adalah media berupa slide presentasi dari aplikasi power point yang menuntut respon dari siswa berupa keterampilan melakukan suatu aktivitas atau perilaku sesuai dengan tuntutan kompetensi.

Beberapa penelitian yang relevan dengan penelitian ini dilakukan oleh (Mandasari, 2021) menemukan bahwa pembelajaran pada Tema 8 menggunakan model pembelajaran berbasis masalah berbantuan media power point dapat meningkatkam aktivitas dan hasil belajar siswa. Penelitian yang dilakukan oleh (Cahyaningsih et al., 2020) menemukan bahwa model Project Based Learning berbantu multimedia power point efektif terhadap hasil belajar siswa. Kemudian penelitian lain juga menemukan bahwa ahwa ada peningkatan hasil belajar IPS setelah menerapkan model pembelajaran Circuit Learning berbantuan media Microsoft Power Point (Putra \& Setiawan, 2019). Tujuan penelitian ini adalah menganalisis model problem based learning bermediakan slide presentasi berbasis unjuk kerja meningkatkan kompetensi pengetahuan IPA dalam pembelajaran daring siswa kelas VI sekolah dasar.

\section{CONCLUSION}

Implementasi model problem based learning bermediakan slide presentasi berbasis unjuk kerja dapat meningkatkan kompetensi pengetahuan IPA. Diharapkan bagi guru agar dapat mempertimbangkan implementasi model problem based learning bermediakan slide presentasi berbasis unjuk kerja sebagai salah satu alternatif strategi pembelajaran yang dapat diterapkan dalam pembelajaran daring, terutama dalam meningkatkan kompetensi pengetahuan IPA siswa. 


\section{REFERENCES}

Atminingsih, D., Wijayanti, A., \& Ardiyanto, A. (2019). Keefektifan Model Pembelajaran PBL Media Audio Visual Terhadap Hasil Belajar IPA Kelas III SDN Baturagung. Mimbar PGSD, 7(2). http://dx.doi.org/10.23887/jjpgsd.v7i2.17560.

Cahyaningsih, R. N., Siswanto, J., \& Sukamto, S. (2020). Keefektifan Model Project Based Learning Berbantu Multimedia Power Point Terhadap Hasil Belajar IPA. Jurnal Penelitian dan Pengembangan Pendidikan, 4(1), 34. https://doi.org/10.23887/jppp.v4i1.25014.

Daheri, M., Juliana, J., Deriwanto, D., \& Amda, A. D. (2020). Efektifitas WhatsApp sebagai Media Belajar Daring. Jurnal Basicedu, 4(4), 775-783. https://doi.org/10.31004/basicedu.v4i4.445.

Diantari, P., Wiarta, I. W., \& Negara, I. G. A. O. (2014). Pengaruh Model Pembelajaran Problem Based Learning Berbasis Hypnoteaching Terhadap Hasil Belajar. Jurnal Mimbar PGSD Universitas Pendidikan Ganesha, 2(1). http://dx.doi.org/10.23887/jjpgsd.v2i1.3103.

Eismawati, E., Koeswanti, H. D., \& Radia, E. H. (2019). Peningkatan hasil belajar matematika melalui model pembelajaran problem based learning (PBL) siswa kelas 4 SD. Jurnal Mercumatika : Jurnal Penelitian Matematika dan Pendidikan Matematika, 3(2), 120. https://doi.org/10.31764/justek.v1i1.416.

Elita, G. S., Habibi, M., Putra, A., \& Ulandari, N. (2019). Pengaruh Pembelajaran Problem Based Learning dengan Pendekatan Metakognisi terhadap Kemampuan Pemecahan Masalah Matematis. Mosharafa: Jurnal Pendidikan Matematika, 8(3), 447-458. https://doi.org/10.31980/mosharafa.v8i3.517.

Jamilah, N. (2019). Pengembangan Media Pembelajaran Power Point Ispring Presenter Pada Materi Kosakata Bahasa Arab Peserta Didik Kelas V MI Tarbiyatul Athfal Lampung Timur. Al Mahāra: Jurnal Pendidikan Bahasa Arab, 5(1), 141-154. https://doi.org/10.14421/almahara.2019.051-08.

Mandasari, N. A. (2021). Penerapan Model Pembelajaran Berbasis Masalah Berbantuan Media Power Point untuk Meningkatkan Aktivitas dan Hasil Belajar Siswa SDN Pandean Lamper 02 Semarang. Jurnal Paedagogy: Jurnal Penelitian Dan Pengembangan Pendidikan, 8(3), 328-337. https://doi.org/10.33394/jp.v8i3.3886.

Minardi, J., \& Akbar, A. S. (2020). Pelatihan Pengembangan Media Pembelajaran Interaktif dengan Power Point untuk Peningkatan Kompetensi Guru SD. E-Dimas: Jurnal Pengabdian Kepada Masyarakat, 11(1), 96. https://doi.org/10.26877/edimas.v11i1.2747.

Nurul Hidayah. (2020). Dampak Sistem Pembelajaran Daring Terhadap Kegiatan Belajar Mengajar Pada Masa Pandemi Covid 19 Di Sdn 3 Sriminosari. As-Salam: Jurnal Studi Hukum Islam \& Pendidikan, 9(2), 189-206. https://doi.org/10.51226/assalam.v9i2.180.

Permata, A., \& Bhakti, Y. B. (2020). Keefektifan Virtual Class dengan Google Classroom dalam Pembelajaran Fisika Dimasa Pandemi Covid-19. JIPFRI (Jurnal Inovasi Pendidikan Fisika dan Riset Ilmiah), 4(1), 27-33. https://doi.org/10.30599/jipfri.v4i1.669.

Pratiwi, E. T., \& Setyaningtyas, E. W. (2020). Kemampuan Berpikir Kritis Siswa Melalui Model Pembelajaran Problem Based Learning dan Model Pembelajaran Project Based Learning. Jurnal Basicedu, 4(2), 379-388. https://doi.org/10.31004/basicedu.v4i2.362.

Putra, C. A., \& Setiawan, M. A. (2019). Penerapan Model Pembelajaran Circuit Learning Berbantuan Media Power Point Terhadap Hasil Belajar. Jurnal Bidang Pendidikan Dasar, 3(1), 1-6. https://doi.org/10.21067/jbpd.v3i1.2958. 
Sadikin, A., \& Hamidah, A. (2020). Pembelajaran Daring di Tengah Wabah Covid-19. Biodik, 6(2), 109-119. https://doi.org/10.22437/bio.v6i2.9759.

Santosa, F. H., Negara, H. R. P., \& Samsul Bahri. (2020). Efektivitas Pembelajaran Google Classroom Terhadap Kemampuan Penalaran Matematis Siswa. Jurnal Pemikiran Dan Penelitian Pendidikan Matematika (JP3M), 3(1), 62-70. https://doi.org/10.36765/jp3m.v3i1.254.

Sariningsih, R., \& Purwasih, R. (2017). Pembelajaran Problem Based Learning Untuk Meningkatkan Kemampuan Pemecahan Masalah Matematis Dan Self Efficacy Mahasiswa Calon Guru. JNPM (Jurnal Nasional Pendidikan Matematika), 1(1), 163. https://doi.org/10.33603/jnpm.v1i1.275.

Suantara, I. K. T., Ganing, N. N., \& Wulandari, I. G. A. A. (2019). Pengaruh Model Pembelajaran Think Pair Share Berbantuan Media TTS terhadap Kompetensi Pengetahuan IPA. Jurnal Ilmiah Sekolah Dasar, 3(4), 473. https://doi.org/10.23887/jisd.v3i4.21783.

Wahidi, A. (2017). Learning Quantum Chemical Model with Learning Media Concept Map and Power Point Viewed from Memory and Creativity Skills Students. JETL (Journal Of Education, Teaching and Learning), 2(1), 159. https://doi.org/10.26737/jetl.v2i1.136.

Windhiyana, E. (2020). Dampak Covid-19 Terhadap Kegiatan Pembelajaran Online Di Perguruan Tinggi Kristen Di Indonesia. Perspektif Ilmu Pendidikan, 34(1), 1-8. https://doi.org/10.21009/pip.341.1.

Wiranti, N. P. D., Suniasih, N. W., \& Darsana, I. W. (2017). Pengaruh Model Pembelajaran Student Facilitator and Explaining Berbantuan Peta Konsep Terhadap Kompetensi Pengetahuan Ipa Siswa. Journal of Education Technology, 1(3), 204. https://doi.org/10.23887/jet.v1i3.12506.

Yunita, N. K. D., \& Tristiantari, N. K. D. (2019). Pengaruh Model Pembelajaran Kooperatif Tipe Tgt Berbasis Kearifan Lokal Tri Hita Karana Terhadap Hasil Belajar. Jurnal $\begin{array}{llll}\text { Pendidikan Multikultural } \quad \text { Indonesia, } & \text { 1(2), }\end{array}$ https://doi.org/10.23887/jpmu.v1i2.20778. 